\title{
The weight gain influence of pregnant women under different clinical conditions on weight at the birth of newborns.
}

Márcia Dornelles Machado Mariot ( $\nabla$ marcia_dornelles@yahoo.com.br )

Universidade Federal do Rio Grande do Sul Faculdade de Medicina https://orcid.org/0000-0002-05914827

\section{Daniela Cortés Kretzer}

Universidade Federal do Rio Grande do Sul Faculdade de Medicina

Isadora Musse Nunes

Universidade Federal do Rio Grande do Sul

Marcelo Zubaran Goldani

Universidade Federal do Rio Grande do Sul Faculdade de Medicina

Juliana Rombaldi Bernardi

Universidade Federal do Rio Grande do Sul Faculdade de Medicina

Clécio Homrich da Silva

Universidade Federal do Rio Grande do Sul Faculdade de Medicina

\section{Research article}

Keywords: Maternal Health, Pregnant Women, Gestational Weight Gain, Birth Weight, Prenatal Care.

Posted Date: September 1st, 2020

DOI: https://doi.org/10.21203/rs.3.rs-54123/v1

License: (c) (1) This work is licensed under a Creative Commons Attribution 4.0 International License.

Read Full License 


\section{Abstract}

BACKGROUND: This study evaluate the influence of weight gain of pregnant women under different clinical conditions (Tobacco, Diabetes mellitus (DM), Hypertension, Intrauterine growth restriction (IUGR) and Control) on the birth weight of newborns.

METHODS: This is an observational, longitudinal study nested in a prospective controlled cohort and conducted from 2011 to 2016 in three hospitals in the city of Porto Alegre (Brazil). Sociodemographic, prenatal (maternal gestational weight gain, among others) and perinatal (birth weight) data from 372 mother-child pairs were analyzed. Pearson's correlation was used to verify the relationship between gestational weight gain and birth weight. Multivariate regression was performed to determine the association between maternal weight gain in the presence of various health conditions and birth weight.

RESULTS: There were no statistical differences in gestational weight gain in different health condition groups $(p=0.092)$. However, women in the Hypertension group had a tendency to gain more weight $(p=$ 0.097). Mothers in the intrauterine growth restriction group gained less weight. A positive correlation was observed between gestational weight gain and birth weight in the Tobacco $(p=0.003)$ and Control $(p$ $=0.001)$ groups, which remained positive only in the Control group after adjustment $(p<0.004)$.

CONCLUSIONS: Only weight gain in pregnant women without clinical changes during pregnancy seemed to influence the weight of the newborn. It is assumed that other factors, such as metabolic or nutritional, present among smoking, diabetes mellitus, hypertensive or with intrauterine growth restriction pregnant women have different modulations on the intrauterine environment and, therefore, exert a different influence on fetal growth.

\section{Background}

Several aspects may influence the prognosis of pregnancy - including the mother's nutritional status during pregnancy. Because of its relationship with newborn nutritional status, as well as with maternal and infant morbidity and mortality outcomes, the mother's nutritional status must be carefully evaluated and monitored by healthcare teams. ${ }^{1,2}$

Inadequate gestational weight gain (both lower and higher than recommended) has been associated with adverse maternal and child outcomes. ${ }^{3}$ A recent systematic review and meta-analysis including over 1 million women has reported that insufficient gestational weight gain was associated with an increase in the number of infants born small for gestational age (SGA) and of premature births. Conversely, excess gestational weight gain was associated with an increase in the number of Cesarean sections and infants born large for gestational age (LGA). ${ }^{4}$

The risk of developing childhood overweight has been associated with maternal weight gain during pregnancy. ${ }^{5}$ However, it is still not entirely clear whether this association is linked to genetic or environmental factors such as maternal lifestyle. ${ }^{6}$ 
In epigenetic terms, the intrauterine environment has been shown to influence fetal and postnatal growth and development, as well as the risk of developing chronic, non-communicable diseases in adulthood. ${ }^{7}$ From a health perspective, maternal lifestyle and prenatal factors should be recognized as important modulators that influence health and disease in offspring and future generations. ${ }^{8}$ As a result, interventions aimed at controlling the mother's nutritional status could potentially reverse these induced epigenetic and phenotypic changes. ${ }^{7}$

Several studies have reported an influence of health conditions during pregnancy on pre and perinatal outcomes. For example, tobacco use may have short-term impacts that include preterm birth, growth restriction, low birth weight, and sudden infant death syndrome; in the long term, tobacco use may cause systemic arterial hypertension, diabetes mellitus and obesity. ${ }^{9}$ According to a systematic review, hypertension may have negative impacts on the child's cardiovascular, immunological, and neurological health. In addition, another study has also shown that gestational hypertension and pre-eclampsia correlate with high blood pressure and lower cognitive function, respectively, in children. ${ }^{10}$

Still regarding the aforementioned repercussions of maternal health conditions during pregnancy, fetal exposure to gestational DM has been associated with the occurrence of macrosomia and obstetric complications at birth, ${ }^{11}$ higher median body mass index (BMI) at birth, ${ }^{12}$ with greater adiposity, ${ }^{13}$ and increased chance of DM in the offspring during childhood and adolescence. ${ }^{14}$ In addition, growth in an intrauterine environment with nutritional and metabolic restrictions produces epigenetic changes, which may, in the long run, promote the development of insulin resistance, obesity, and dyslipidemia. ${ }^{15}$

Considering the body of evidence linking inadequate gestational weight gain with unfavorable maternal and child health outcomes, it is relevant to inquire whether the association of certain health conditions with inadequate gestational weight gain will also impact birth weight. Thus, the objective of the present study was to To evaluate the influence of weight gain of pregnant women under different clinical conditions (Tobacco, Diabetes mellitus, Hypertension, Intrauterine growth restriction and Control) on the birth weight of newborns.

\section{Methods}

This is an observational, longitudinal study nested in a prospective controlled cohort project titled "Perinatal impact of different intrauterine environments in the first half of the child's life and development - IVAPSA study." The IVAPSA followed mothers and newborns to investigate the impact of adverse intrauterine environments on the growth and development of children. The study design and methods have been published elsewhere. ${ }^{16}$ And, more recently, its development and data collection processing. ${ }^{17}$

A convenience sample consisting of 400 mother-child pairs was recruited. Participants were distributed into five maternal health condition groups: Hypertension, DM, IUGR, Tobacco smoking, and Control (this last one, without any condition of the other groups) The pregnant women were recruited from three public hospitals in Porto Alegre: Hospital de Clínicas de Porto Alegre (HCPA), Hospital Fêmina, and Hospital 
Nossa Senhora da Conceição, the last two belonging to the same group Hospital Conceição Group (GHC). All three hospitals serve populations with similar sociodemographic characteristics, providing prenatal assistance and deliveries for high-risk pregnancies.

HIV-positive women, those with multiple pregnancies or premature births ( $<37$ weeks), as well as newborns with acute illnesses or congenital malformations were not included in the study. The selection criteria for inclusion in the study groups, recruitment, and interviews are described in detail in the original article by Bernardi et al. ${ }^{16}$

The IVAPSA cohort recruited 400 mother-child pairs, each allocated into one of five health condition groups. Twenty-eight mother-child pairs meeting the criteria for more than one group concomitantly were characterized as a "multiple criterion group" and were excluded from the study. Sample selection is described in Figure 1.

\section{Data collection}

The first interviews were performed 24-48 hours after birth. In addition to the information provided by the mothers, the prenatal card and the medical records of the mother and newborn were also reviewed.

Information was collected on maternal sociodemographic characteristics (skin color, marital status, age, schooling, and family income) and prenatal care (parity, gestational age, number of prenatal consultations), gestational weight gain, perinatal information (type of birth, weight, length, Apgar score, and adequacy of birth weight for gestational age).

The final gestational age (GA) variable resulted from the combination, in order of obstetric importance, of the following: newborn gestational age determined by the Capurro method, obstetric ultrasound and last menstruation date. Parity was defined as the number of previous children. The variable "pre-gestational overweight" was defined by combining the World Health Organization (WHO) overweight and obesity BMI categories. ${ }^{18}$ Gestational weight gain was calculated by subtracting the last weight measured by the medical team during pregnancy from the pre-pregnancy weight recorded in the in the prenatal portfolio.

\section{Statistical analysis}

The main outcome measure was newborn weight (in grams). The Kolmogorov-Smirnov test was applied to assess whether the distribution of the studied variables was normal. Continuous variables were described as mean and standard deviation when parametric; for non-parametric variables, median and interquartile range were used. Categorical variables were described as absolute number and frequency. The test used to verify the association of parametric variables was ANOVA. For non-parametric variables, Kruskal-Wallis was used. To compare categorical variables between groups, the Tukey test with Dunn's post hoc test was used. 
Pearson's correlation was used to verify the relationship between gestational weight gain and newborn weight. Multivariate regression evaluated the association between gestational weight gain and the newborn's weight according to each adverse intrauterine environment, and adjusted for maternal age, family income, smoking in the previous pregnancy, number of prenatal visits, and GA. A significance level of $5 \%$ was adopted. Processing and analysis were performed using the Statistical Package for the Social Sciences-(SPSS) version 21.0.

\section{Ethical considerations}

The IVAPSA study was approved by the Ethics Committees at HCPA (protocol 11-0097) and GHC (protocol 11-027). The study protocol is in accordance with Brazilian guidelines and regulations

governing human research. ${ }^{19}$ At the time of recruitment, all women received a comprehensive explanation regarding the study objectives and protocol, and were ensured the possibility of leaving the study without any compromising their care. After signature of the informed consent form, the mother-child pair was included in the study.

\section{Results}

The study included 372 mother-child pairs distributed into five groups. Table 1 shows socio-demographic, maternal, gestational, and perinatal characteristics of the sample. Significant differences were noted among the groups regarding maternal age $(p=0.001)$, marital status $(p=0.007)$, maternal education $(p=$ $0.002)$, family income $(p<0.001)$, parity $(p=0.003)$, overweight pre-pregnancy $(p<0.001)$, smoking in the previous pregnancy $(p<0.001)$, number of prenatal consultations $(p<0.001)$, gestational age $(p=0.051)$, type of birth $(p<0.001)$, birth weight $(p<0.001)$, and length at birth $(p<0.001)$.

Mean maternal age was significantly higher in the DM and hypertension groups. The highest prevalence of excess gestational weight gain and the highest number of prenatal visits were observed in the DM group. Vaginal delivery was more frequent in the tobacco, control, IUGR and DM groups, while Cesarean delivery was more frequent in the hypertension group. The highest mean birth weight was recorded in the DM group. The control group had the highest mean birth length.

Median parity was lowest in the IUGR group. That group also had the lowest prevalence of overweight and the highest mean gestational age. Participants in the tobacco group had less favorable indicators compared to the other groups regarding marital status with partner, education, family income, number of prenatal consultations, and birth weight and length.

Table 1 - Socio-demographic and maternal characteristics, prenatal and perinatal data and gestational weight gain in different intrauterine environment groups 


\begin{tabular}{|c|c|c|c|c|c|c|c|}
\hline \multirow[t]{2}{*}{ Variables } & $\begin{array}{l}\text { Overall } \\
\text { sample } \\
(\mathrm{n}=372)\end{array}$ & $\begin{array}{c}\mathrm{DM} \\
(\mathrm{n}=62)\end{array}$ & $\begin{array}{l}\text { Hypertension } \\
\qquad(\mathrm{n}=26)\end{array}$ & $\begin{array}{l}\text { Tobacco } \\
(\mathrm{n}=87)\end{array}$ & $\begin{array}{l}\text { IUGR } \\
(\mathrm{n}=36)\end{array}$ & $\begin{array}{l}\text { Control } \\
(\mathrm{n}=161)\end{array}$ & $\mathrm{P}$ \\
\hline & $\mathrm{n}(\%)$ & $\mathrm{n}(\%)$ & $\mathrm{n}(\%)$ & $\mathrm{n}(\%)$ & $\mathrm{n}(\%)$ & $\mathrm{n}(\%)$ & \\
\hline \multicolumn{8}{|l|}{$\begin{array}{l}\text { Maternal/sociodemographic } \\
\text { characteristics }\end{array}$} \\
\hline $\begin{array}{l}\text { Maternal age (years) - } \\
\mathrm{x} \pm \mathrm{SD}\end{array}$ & $25.9 \pm 6,5$ & $\begin{array}{c}28.2 \pm \\
5.8^{\mathrm{b}}\end{array}$ & $28.7 \pm 6.9^{b}$ & $\begin{array}{c}24.6 \pm \\
5.7^{\mathrm{a}}\end{array}$ & $\begin{array}{c}23.9 \pm \\
6.0^{\mathrm{a}}\end{array}$ & $\begin{array}{c}25.7 \pm \\
6.9^{\mathrm{ab}}\end{array}$ & 0.001 \\
\hline Skin color (self-report)- n(\%) & & & & & & & 0.268 \\
\hline White & $223(59.9)$ & $\begin{array}{c}40 \\
(64.5)\end{array}$ & $18(69.2)$ & $\begin{array}{c}51 \\
(58.6)\end{array}$ & $\begin{array}{c}16 \\
(44.4)\end{array}$ & $\begin{array}{c}98 \\
(60.9)\end{array}$ & \\
\hline Non-white & $149(40.1)$ & $\begin{array}{c}22 \\
(35.5)\end{array}$ & $8(30.8)$ & $\begin{array}{c}36 \\
(41.4)\end{array}$ & $\begin{array}{c}20 \\
(55.6)\end{array}$ & $\begin{array}{c}63 \\
(39.1)\end{array}$ & \\
\hline Marital status - n(\%) & & & & & & & 0.007 \\
\hline With partner & $296(79.6)$ & $\begin{array}{c}52 \\
(83.9)\end{array}$ & $21(80.8)$ & $\begin{array}{c}57 \\
(65.5)\end{array}$ & $\begin{array}{c}30 \\
(83.3)\end{array}$ & $\begin{array}{c}136 \\
(84.5) *\end{array}$ & \\
\hline Without partners & $76(20.4)$ & $\begin{array}{c}10 \\
(16.1)\end{array}$ & $5(19.2)$ & $\begin{array}{c}30 \\
(34.5)^{*}\end{array}$ & $6(16.7)$ & $\begin{array}{c}25 \\
(15.5)\end{array}$ & \\
\hline $\begin{array}{l}\text { Maternal schooling (years) - } \\
\mathrm{x} \pm \text { DP }\end{array}$ & $9.3 \pm 2.7$ & $\begin{array}{c}10.0 \pm \\
3.2^{\mathrm{b}}\end{array}$ & $9.1 \pm 2.9^{a b}$ & $\begin{array}{c}8.4 \pm \\
2.6^{\mathrm{a}}\end{array}$ & $\begin{array}{l}9.7 \pm \\
2.2^{\mathrm{ab}}\end{array}$ & $\begin{array}{l}9.5 \pm \\
2.5^{\mathrm{ab}}\end{array}$ & 0.002 \\
\hline $\begin{array}{l}\text { Family income }(\mathrm{R} \$) \text { - median } \\
(\mathrm{P} 25 \text { - P75) }\end{array}$ & $\begin{array}{l}1600 \\
(1000- \\
2500)\end{array}$ & $\begin{array}{l}1500^{b} \\
(1100- \\
2900)\end{array}$ & $\begin{array}{c}1500 \\
(950-2250)\end{array}$ & $\begin{array}{l}1240^{\mathrm{a}} \\
(800- \\
1900)\end{array}$ & $\begin{array}{l}1600 \\
(1085- \\
3000)\end{array}$ & $\begin{array}{l}2000^{b} \\
(1210- \\
3000)\end{array}$ & $<0.001$ \\
\hline \multicolumn{8}{|l|}{ Prenatal and perinatal data } \\
\hline $\begin{array}{l}\text { Smoking in previous } \\
\text { pregnancy (\%) }\end{array}$ & $56(15.1)$ & $5(8.1)$ & $2(7.7)$ & $\begin{array}{c}42 \\
(48.3)^{*}\end{array}$ & $1(2.8)$ & $6(3.7)$ & $<0.001$ \\
\hline Planned pregnancy - n (\%) & $130(34.9)$ & $\begin{array}{c}29 \\
(46.8) *\end{array}$ & $10(38.5)$ & $\begin{array}{c}14 \\
(16.1)\end{array}$ & $\begin{array}{c}14 \\
(38.9)\end{array}$ & $\begin{array}{c}63 \\
(39.1)\end{array}$ & 0.001 \\
\hline No. of prenatal visits $-\mathrm{x} \pm \mathrm{SD}$ & $8.0 \pm 3.2$ & $\begin{array}{c}9.8 \pm \\
3.5^{\mathrm{c}}\end{array}$ & $9.2 \pm 2.7^{\mathrm{bc}}$ & $\begin{array}{c}6.4 \pm \\
2.8^{\mathrm{a}}\end{array}$ & $\begin{array}{l}7.6 \pm \\
3.1^{\mathrm{ab}}\end{array}$ & $\begin{array}{c}8.1 \pm \\
2.9^{b}\end{array}$ & $<0.001$ \\
\hline GA (weeks) - x \pm SD & $39.1 \pm 1.2$ & $\begin{array}{c}39.0 \pm \\
1.2\end{array}$ & $38.6 \pm 1.1$ & $\begin{array}{c}39.2 \pm \\
1.3\end{array}$ & $\begin{array}{c}38.9 \pm \\
1.3\end{array}$ & $\begin{array}{c}39.3 \pm \\
1.2\end{array}$ & 0.051 \\
\hline Parity - median (P25 - P75) & $2(0-2)$ & $\begin{array}{c}2(0- \\
3)^{a b}\end{array}$ & $2(0-3)^{a b}$ & $\begin{array}{c}2(0- \\
3)^{b}\end{array}$ & $\begin{array}{c}0(0- \\
2)^{\mathrm{a}}\end{array}$ & $\begin{array}{c}1(0- \\
2)^{a b}\end{array}$ & 0.003 \\
\hline Type of delivery - n(\%) & & & & & & & 0.001 \\
\hline Vaginal & $246(66.1)$ & $\begin{array}{c}34 \\
(54.8)\end{array}$ & $9(34.6)$ & $\begin{array}{c}65 \\
(74.7)\end{array}$ & $\begin{array}{c}24 \\
(66.7)\end{array}$ & $\begin{array}{c}114 \\
(70.8)\end{array}$ & \\
\hline C-section & $126(33.9)$ & $\begin{array}{c}28 \\
(45.2)^{*}\end{array}$ & $17(65.4)^{*}$ & $\begin{array}{c}22 \\
(25.3)\end{array}$ & $\begin{array}{c}12 \\
(33.3)\end{array}$ & $\begin{array}{c}47 \\
(29.2)\end{array}$ & \\
\hline Newborn sex & & & & & & & 0.892 \\
\hline Male & $172(46.2)$ & $\begin{array}{c}29 \\
(46.8)\end{array}$ & $12(46.2)$ & $\begin{array}{c}44 \\
(50.6)\end{array}$ & $\begin{array}{c}15 \\
(41.7)\end{array}$ & $\begin{array}{c}72 \\
(44.7)\end{array}$ & \\
\hline Female & $200(53.8)$ & $\begin{array}{c}33 \\
(53.2)\end{array}$ & $14(53.8)$ & $\begin{array}{c}43 \\
(49.4)\end{array}$ & $\begin{array}{c}21 \\
(58.3)\end{array}$ & $\begin{array}{c}89 \\
(55.3)\end{array}$ & \\
\hline Birth weight $(g)-x \pm S D$ & $\begin{array}{c}3242 \pm \\
500\end{array}$ & $\begin{array}{c}3451 \pm \\
453^{c}\end{array}$ & $3265 \pm 523^{b c}$ & $\begin{array}{c}3114 \pm \\
403^{b}\end{array}$ & $\begin{array}{c}2528 \pm \\
173^{\mathrm{a}}\end{array}$ & $\begin{array}{c}3385 \pm \\
450^{\mathrm{c}}\end{array}$ & $<0.001$ \\
\hline Birth length - X \pm SD & $48.6 \pm 2.2$ & $\begin{array}{l}49.0 \pm \\
1.9^{\mathrm{bc}}\end{array}$ & $48.4 \pm 1.9^{\mathrm{bc}}$ & $\begin{array}{l}48.0 \pm \\
2.3^{\mathrm{b}}\end{array}$ & $\begin{array}{l}46.1 \pm \\
1.6^{\mathrm{a}}\end{array}$ & $\begin{array}{c}49.3 \pm \\
2.0^{\mathrm{c}}\end{array}$ & $<0.001$ \\
\hline
\end{tabular}




\begin{tabular}{lccccccc} 
Pre-gestational overweight - & $153(45.3)$ & 43 & $13(56.5)$ & 34 & $7(20.6)$ & 56 & $<0.001$ \\
$\mathrm{n}(\%)$ & & $(74.1)^{*}$ & & $(43.6)$ & & $(38.6)$ & \\
\hline Gestational weight gain- Kg & $13.6 \pm 7.2$ & $13.1 \pm$ & $16.9 \pm 6.0$ & $13.8 \pm$ & $11.3 \pm$ & $13.6 \pm$ & 0.092 \\
& & 8.4 & & 6.7 & 5.5 & 7.1 & \\
\hline
\end{tabular}

ANOVA was used to compare parametric continuous variables, and the Kruskal-Wallis test to compare nonparametric continuous variables. SD: standard

*Statistically significant according to adjusted residual tests at 5\%. ${ }^{a, b, c}$ Equal superscript letters denote no difference at 5\% significance by Tukey's or Dunn's test. GA: defined by a combination of the following: newborn gestational age according to the Capurro method, obstetric ultrasound (USG) and last menstruation date (LMP).

There were no statistically significant differences in terms of gestational weight gain between the five groups $(p=0.092)$. However, there was a trend towards greater weight gain among pregnant women in the hypertension group $(p=0.097)$, and towards less weight gain in the IUGR group $(p=0.269)($ Table 1$)$. As expected, it was observed that birth weight was lower among pregnant women in the IUGR group compared to the other groups $(\mathrm{p}<0.001)$. It was also observed that the newborns in the tobacco group had significantly lower birth weight when compared to the DM and control groups (Figure 2).

There was a positive correlation between gestational weight gain and birth weight of newborns in the tobacco $(p=0.003)$ and control $(p=0.001)$ groups. There were no correlations between the variables studied in the DM and IUGR groups (Table 3 ).

Table 3 - Correlation between gestational weight gain and birth weight of newborns from different intrauterine groups

\begin{tabular}{lc}
\hline \multicolumn{1}{c}{ Study group } & Pearson correlation coefficient $(\mathrm{p})$ \\
\hline DM $(\mathrm{n}=58)$ & $\mathrm{r}=0.192(\mathrm{p}=0.150)$ \\
Hypertension $(\mathrm{n}=26)$ & $\mathrm{r}=0.332(\mathrm{p}=0.097)$ \\
\hline Tobacco $(\mathrm{n}=78)$ & $\mathrm{r}=0.337(\mathrm{p}=0.003)$ \\
\hline IUGR $(\mathrm{n}=33)$ & $\mathrm{r}=0.198(\mathrm{p}=0.269)$ \\
Control $(\mathrm{n}=151)$ & $\mathrm{r}=0,260(\mathrm{p}=0,001)$ \\
\hline Total $(\mathrm{n}=372)$ & $\mathrm{r}=0.235(\mathrm{p}<0.001)$ \\
\hline
\end{tabular}

There was an association between gestational weight gain and birth weight in the Control group $(\mathrm{p}<$ 0.004) after adjustment for maternal age, family income, number of prenatal consultations, smoking in the previous pregnancy, and final gestational age (Table 4).

Table 4 - Multivariate linear regression analysis to assess the influence of gestational weight gain on birth weight of newborns per group 


\begin{tabular}{lccc}
\hline Study group & $\mathrm{b}^{*}(95 \mathrm{CI} \%)$ & Beta $(\beta)$ & $\mathrm{p}$ \\
\hline DM $(\mathrm{n}=58)$ & $15.3(-4.3$ a 35.0$)$ & 0.287 & 0.123 \\
Hypertension $(\mathrm{n}=26)$ & $42.8(-14.7$ a 100.3$)$ & 0.432 & 0.134 \\
\hline Tobacco $(\mathrm{n}=78)$ & $10.6(-4.6$ a 25.8$)$ & 0.175 & 0.169 \\
\hline IUGR $(\mathrm{n}=33)$ & $2.7(-13.4-18.8)$ & 0.071 & 0.733 \\
\hline Control $(\mathrm{n}=151)$ & $15.0(4.9$ a 25.2$)$ & 0.236 & 0.004 \\
\hline Total $(\mathrm{n}=372)$ & $15.5(8.1$ a 22.9$)$ & 0.220 & $<0.001$ \\
\hline
\end{tabular}

*Adjusted for number of prenatal care visits, maternal age, smoking during prior pregnancy, family income, and GA. GA: defined by a combination of the following: newborn gestational age according to the Capurro method, obstetric ultrasound (USG) and last menstruation date (LMP).

\section{Discussion}

In our study, the relationship between gestational weight gain and newborn weight differed according to exposure to different intrauterine environments resulting from the presence of various health conditions. In pregnant women in the Tobacco and Control groups, weight gain was significantly associated with birth weight. Particularly, in the Control group, for each kilogram of weight acquired by the pregnant woman, there was an increase of 236 grams in the birth weight of these newborns. The Tobacco group had the poorest indicators in terms of maternal education, family income, pregnancy planning, and number of prenatal consultations were observed. In contrast, pregnant women in the DM and hypertension groups had a higher number of prenatal consultations, possibly because they were referred to high-risk prenatal care. Pregnant women in the hypertension group had greater gestational weight gain and a higher prevalence of Cesarean birth, followed by those in the Tobacco and Control groups.

Concerning sociodemographic characteristics, it was observed that pregnant women in the Tobacco and IUGR groups were the youngest, while those in the DM and hypertension groups were the oldest. The lowest income was observed among the women in the Tobacco group. The women in the Control group had the highest presence of a partner, and those in the Tobacco group had the least presence. Pregnant women in the Tobacco group had less education, while those in the DM group had a higher level of education. In addition, the Tobacco group had less pregnancy planning and fewer prenatal consultations, whereas those in the DM group had the most pregnancy planning and performed the highest number of consultations.

According to a study carried out by Ferreira et al. ${ }^{20}$ in the city of Porto Alegre, Brazil, aiming to analyze the factors associated with the number of prenatal consultations in smoking and non-smoking women, smoking during pregnancy was especially associated with the most unfavorable socioeconomic conditions, reinforcing the need for qualified prenatal care, aimed at identifying vulnerabilities and supporting these pregnant women. The number of prenatal visits is associated with unfavorable maternal and child outcomes. Pregnant women who had less than seven prenatal consultations showed a greater chance of their children being born premature, with low weight and even of the occurrence of 
perinatal death. ${ }^{21}$ In the present study, children of smoking mothers had a mean of 6.7 prenatal consultations during pregnancy, and their offspring had significantly lower birth weight as compared to the newborns in the DM, Hypertension, and Control groups.

Banderali et al. ${ }^{9}$ have described the following effects of maternal smoking during pregnancy on the child's conception: premature birth, restricted intrauterine growth, and low birth weight. In regards to the child, the effects included sudden death syndrome, neurological and behavioral development problems, obesity, systemic arterial hypertension, DM type 2, impaired lung function, and asthma. In view of these findings, the authors highlight the importance of guidance on quitting smoking for women, especially during the prenatal and postpartum periods. ${ }^{9}$

Pregnant women with a lower level of education had a higher risk of inadequate gestational weight gain. In this group, dietary interventions proved to be the most appropriate choice, according to a meta-analysis carried out by O'Brien et al. ${ }^{22}$ The present results corroborate these meta-analytic findings, given that pregnant women in the Hypertension and Tobacco groups had significantly less education and greater gestational weight gain.

In this study, the prevalence of Cesarean sections was higher in pregnant women in the Hypertension and DM groups. Research carried out to investigate the factors associated with the type of delivery in a mixed (public and private) hospital in the northeast region of the Brazilian state of Rio Grande do Sul found Cesarean section prevalence rates of 79.1 and $69.2 \%$, respectively, for pregnant women with hypertensive disorders and diabetes in the current pregnancy. ${ }^{23}$ These findings are in agreement with the results of the present study, since pregnant women in the Hypertension group, followed by those with DM, were the ones with the highest prevalence of Cesarean sections.

The literature shows that pre-gestational BMI is directly associated with gestational weight gain. ${ }^{24}$ In the present study, the women with the highest prevalence of pre-gestational overweight were those in the DM and Hypertension groups; gestational weight gain was higher in those of the Hypertension, Tobacco, Control, and DM groups. The DM group had better obstetric and perinatal health outcomes compared to the Hypertension group, suggesting that greater control over feeding during pregnancy may have contributed to better maternal and child health conditions.

Women in the DM group had the highest rates of pre-pregnancy overweight. According to a meta-analysis survey with data from 37 studies of pregnancy and birth cohort conducted in Europe, North America, and Australia, pre-pregnancy maternal nutritional status, together with gestational weight gain were associated with increased risk of overweight and obesity during childhood. However, the authors state that the causal associations and the mechanisms involved in this process have not yet been fully elucidated. ${ }^{24} \mathrm{~A}$ systematic review study with meta-analysis carried out by Goldstein et al. ${ }^{3}$ also found an association between maternal weight gain and postpartum weight retention with offspring obesity. 
Similarly, the combination of excessive weight gain during pregnancy and metabolic comorbidities (type 1, 2 DM and gestational diabetes) has been correlated with the birth of newborns considered to be large for their gestational age. In contrast, insufficient gestational weight gain has been linked to the birth of newborns considered SGA. Thus, interventions aimed at adequate gestational weight gain are important and will prevent unfavorable maternal and child outcomes. ${ }^{25}$

No statistically significant differences were found in maternal gestational weight gain between the various groups studied. However, a tendency was noted for pregnant women in the Hypertension group to present greater weight gain. According to studies in China and Brazil, higher rates of pre-gestational body mass and gestational weight gain increase the risk of hypertensive syndromes during pregnancy, ${ }^{26}$ demonstrating a possible correlation between weight gain during pregnancy and hypertensive diseases. In this context, according to the present results, it is possible to assume that monitoring of weight gain among pregnant women with hypertension is not effective. In the present study, although our hypertensive participants had been referred to high-risk prenatal services, like those in the DM group, they had a number of consultations lower than the pregnant women in the DM group, but higher in comparison to the other groups. Therefore, it is believed that the prenatal care provided to them is strongly directed to the control of blood pressure levels, with no attention to dietary control.

A study carried out in the state located in the extreme south of Brazil with the objective of measuring the prevalence and identifying factors associated with adequate weight gain during pregnancy demonstrated that prenatal care was not effective in controlling weight gain in pregnant woman, even though most of them attended more than six consultations during prenatal care. The authors highlight that, in view of the low prevalence of women with adequate weight gain during pregnancy, it is necessary to improve the quality of prenatal care services. ${ }^{27}$

Among the clinical conditions studied, the highest mean weight was found in newborns in the DM group. This is similar the results reported by Martino et al., ${ }^{28}$ who found that a high concentration of glucose in the maternal body with diabetes induced an increase in fetal growth. In contrast, the newborns in the IUGR group, followed by the Tobacco group, had the lowest birth weight. These results were also previously observed in a cohort study carried out in Bahia, a state in the Northeast of Brazil, which aimed to assess the association between smoking and other factors during pregnancy with birth weight and childhood. In that study, maternal smoking during pregnancy was associated with insufficient weight gain of the pregnant woman and with low birth weight. ${ }^{29}$ Still in this context, according to studies carried out in Spain and Brazil, each additional unit of tobacco consumed daily in the third trimester led to a 32-g reduction in birth weight ${ }^{30}$; also, the newborns of smoking mothers presented on average $258 \mathrm{~g}$ less weight when compared to those of non-smokers. ${ }^{31}$

Weight gain during pregnancy was associated with birth weight in pregnant women in the Tobacco and Control groups in the crude analyzes. However, in an adjusted model, only the weight gain of pregnant women in the Control group maintained a significant association with the weight of the newborn. This 
result supports the influence of gestational health conditions on fetal growth, possibly through intrauterine modulation of metabolic.

Maternal BMI and gestational weight gain have a positive correlation with the newborn's birth weight. ${ }^{24,25}$ This is corroborated by the findings of the present study, in which an increase of $1 \mathrm{~kg}$ in gestational weight gain was associated with an increase of $236 \mathrm{~g}$ in the weight of newborns in the Control group. This confirms the influence of maternal weight gain during pregnancy on birth weight. In this sense, according to a study by Van Rossem et al., ${ }^{5}$ the excessive maternal weight gain during pregnancy, as well as its increase after the birth, demonstrated that children born to mothers with gestational weight gain excessive weight and that they gained weight after childbirth had a higher prevalence of overweight in childhood and adolescence.

Still, according to Dimert et al., ${ }^{32}$ in an investigation conducted in Germany, the association of maternal weight gain with newborn weight was mainly attributed to the fact that most pregnant women did not adequately follow dietary recommendations and as a result developed a weight gain above desirable levels during pregnancy. Interventions with strategies aimed at reducing risk factors for the development of childhood obesity (e.g., excessive weight gain in pregnancy, macrosomia, rapid weight gain in childhood, smoking during pregnancy, and non-adherence to nutrition and sleep recommendations) are important alternatives for disease prevention. ${ }^{33}$

Training of the multidisciplinary team, especially physicians, nurses, and nutritionists who work in prenatal care, must be prioritized in order to ensure the quality of prenatal care, which must also include an appropriate nutritional assessment. This would mainly involve the detection and early intervention to prevent risk situations associated with nutritional issues in pregnancy, in addition to attention to psychosocial aspects and educational and preventive activities. Likewise, swift referral to services specializing in gestational diseases should be ensured throughout the prenatal care. ${ }^{34,35}$

Finally, the importance of nutritional monitoring during prenatal care is emphasized, which includes nutritional assessment and monitoring for appropriate gestational weight gain ${ }^{36}$ and the encouragement of adequate dietary practices ${ }^{37,38}$ in order to prevent inadequacies in weight gain during pregnancy and, therefore, avoid negative pregnancy outcomes. ${ }^{2}$

\section{Conclusions}

Weight gain in pregnant women without clinical changes during pregnancy influenced birth weight. It is assumed that other factors, such as metabolic or nutritional, may have modulated intrauterine environments in the presence of smoking, diabetes, hypertension or intrauterine growth restriction, with direct impacts on fetal growth.

For that reason, prenatal monitoring of pregnant women with interventions and adequate and effective monitoring of weight gain during pregnancy is essential in order to reduce the negative impact of 
inadequate gestational weight gain on maternal and child health in the short and long terms.

\section{Abbreviations}

DM: Diabetes Mellitus; IUGR: Intra-uterine Growth Restriction; SGA: Small for Gestational Age; LGA: Large for Gestational Age; BMI: Body Mass Index; IVAPSA: Impact of perinatal environment variations on the health of the newborn in the first 6 months of life; HCPA: Hospital de Clínicas de Porto Alegre; GHC: Grupo Hospitalar Conceição; GA: Gestational Age; WHO: World Health Organization; SPSS: Statistical Package for Social Sciences; USG: Obstetric Ultrasound; LMD: Last Menstruation Date (LMP).

\section{Declarations}

Ethics approval and consent to participate: Ethical approval and consent to participate the present study was approved by the Research Ethics Committees of Hospital de Clínicas de Porto Alegre under protocol number 11-0097 and by Grupo Hospitalar Conceição under protocol number 11-027. Registration on the Brazilian Research Platform: 65190217.5.0000.5327. Participants were included in the study only after written informed consent.

Consent for publication: Not applicable.

Availability of data and materials: The data set used and analyzed in the present study are under the responsibility of the corresponding author and available upon reasonable request.

Competing interests: The authors declare that there is no competing of interest.

Funding: The study was funded by FAPERGS/CNPq 10/0018.3 (National Council for Scientific and Technological Development), PRONEX 2009 (Support Program for Centers of Excellence), FIPE/HCPA (Research Incentive Fund and Hospital de Clínicas de Porto Alegre) and CAPES (Commission for the Improvement of Higher Education Personnel). The institution reviewed the proposal, provided laboratory space and equipment, data analysis and manuscript development.

Authors' contributions: MDMM: Conceptualization, Methodology, Formal analysis, Investigation, Writing Review \& Editing, Visualization, Supervision, Funding acquisition. DCK: Writing - Original Draft, Methodology, Investigation, Visualization. IMN: Writing - Original Draft, Investigation.

MZG: Conceptualization, Methodology, Funding acquisition, Project administration JRB:

Conceptualization, Methodology, Funding acquisition CHS: Conceptualization, Methodology, Formal analysis, Writing - Reviewing \& Editing, Project administration, Funding acquisition.

All authors read and approved the final manuscript.

Acknowledgements: Acknowledgement for the important support received from the Research and PostGraduation Group of the Hospital de Clínicas de Porto Alegre in the various stages of research 
development. We also thank the researchers of the IVAPSA group involved in all stages of the study's development.

Authors' information: MDMM: PhD student. Federal University of Rio Grande do Sul. Faculty of Medicine. Postgraduate Program in Child and Adolescent Health. Porto Alegre, Brazil. DCK: master's student. Federal University of Rio Grande do Sul. Faculty of Medicine. Postgraduate Program in Child and Adolescent Health. Porto Alegre, Brazil. IMN: Graduation student. Federal University of Rio Grande do Sul. Faculty of Nursing. Porto Alegre, Brazil. MZG: Full Professor, Department of Pediatrics and Child and Adolescent Health Program, Center for Child and Adolescent Health Studies, Hospital de Clínicas de Porto Alegre (HCPA), Universidade Federal do Rio Grande do Sul (UFRGS). JRB: Assistant Professor, Department of Nutrition, Child and Adolescent Health Program and Food, Nutrition and Health Program, Center for Child and Adolescent Health Studies, Hospital de Clínicas de Porto Alegre (HCPA), Universidade Federal do Rio Grande do Sul (UFRGS). 区CHS: Associate Professor, Department of Pediatrics and Child and Adolescent Health Program, Center for Child and Adolescent Health Studies, Hospital de Clínicas de

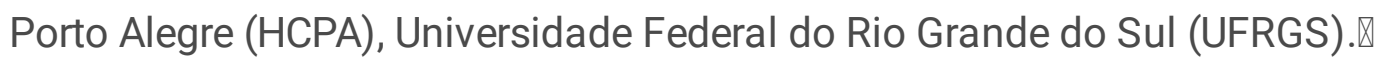

\section{References}

1. Freitas HBM, Lima, RF, Targino MVP, Targino ALVP, Nascimento AT, Vasconcelos LPF, et al. A influência do estado nutricional durante o período gestacional e sua correlação no peso do recémnascido. Rev Eletrônica Acervo Saúde. 2018 dez 30; 19:1-9. Doi: 25248/reas.e206.2019

2. Knob JI, Bottaro SM, Kirchner RM. Correlação entre o estado antropométrico materno e o do recémnascido. Rev da Associação Brasileira de Nutrição. 2016 Jul-Dez; 7(2): 31-37. ISSN 2177-7527 (online)

3. Goldstein RF, Abell SK, Ranasinha S, Misso M, Boyle JA, Black MH, et al. Association of Gestational Weight Gain With Maternal and Infant Outcomes: A Systematic Review and Meta-analysis. JAMA. 2017 Jun 6;317(21):2207-2225. Doi: 10.1001/jama.2017.3635.

4. Goldstein RF, Abell SK, Ranasinha S, Misso ML, Boyle JA, Harrison CL, et al. Gestational weight gain across continents and ethnicity: systematic review and meta-analysis of maternal and infant outcomes in more than one million women. BMC Med. 2018 Aug 31;16(1):153. Doi: 10.1186/s12916018-1128-1.

5. Rossem LV, Wijga AH, Gehring U, Koppelman GH, Smit HA. et al. Maternal Gestational and Post delivery Weight Gain and Child Weight. Pediatrics. 2015 Nov.136(5):1294-1301. Doi: 10.1186/s12916-018-1128-1.

6. Lawrence GM, Shulman S, Friedlander Y, et al. Associations of maternal pre-pregnancy and gestational body size with offspring longitudinal change in BMI. Obesity (Silver Spring). 2014; 22(4): 1165-1171. Doi: 1002/oby.20643.

7. Godfrey KM, Lillycrop KA, Burdge GC, Gluckman PD, Hanson MA, et al. Non-imprinted epigenetics in fetal and postnatal development and growth. Nestle Nutr Inst Workshop Ser. 2013; 71:57-63. Doi: 
$1159 / 000342552$.

8. Barua S, Junaid MA. Lifestyle, pregnancy and epigenetic effects. Epigenomics 2015; 7(1): 85-102. Doi: 2217/epi.14.71.

9. Banderali G, Martelli A, Landi M, Moretti F, Betti F, Radaelli G, et al. Short and long term health effects of parental tobacco smoking during pregnancy and lactation: a descriptive review. J Transl Med. 2015 Oct 15; 13:327. Doi: 10.1186/s12967-015-0690-y.

10. Pinheiro TV, Brunetto S, Ramos JG, Bernardi JR, Goldani MZ, et al. Hypertensive disorders during pregnancy and health outcomes in the offspring: a systematic review. J Dev Orig Health Dis. 2016; 7(4): 391-407. Doi: 1017/S2040174416000209.

11. Plows JF, Stanley JL, Baker PN, Reynolds CM, Cickers MH, et al. The Pathophysiology of Gestational Diabetes Mellitus. Int J Mol Sci. Oct 2018; 19(11): 3342. Doi: 3390/ijms19113342.

12. Nouhjah S, Shahbazian H, Latifi SM, Malamiri RA, Ghodrati N, et al. Body mass index growth trajectories from birth through 24 months in Iranian infants of mothers with gestational diabetes mellitus. Diabetes Metab Syndr. 2019 Jan - Feb; 13(1):408-412. Doi: 10.1016/j.dsx.2018.10.002.

13. Chang Y, Chen X, Zhang ZK. Intrauterine Exposure to Maternal Diabetes is Associated with Adiposity in Children at 6 Years of Age in China. Biomed Environ Sci. 2015 Feb; 28(2):140-2. Doi: 3967/bes2015.017.

14. Blotsky AL, Rahme E, Dahhou M, Nakhla M, Dasgupta K, et al. Gestational diabetes associated with incident diabetes in childhood and youth: a retrospective cohort study. CMAJ. 2019 Apr 15;191(15):E410-E417. Doi: 10.1503/cmaj.181001.

15. Kopec G, Shekhawat PS, Mhanna MJ. Prevalence of diabetes and obesity in association with prematurity and growth restriction. Diabetes Metab Syndr Obes. 2017 jul; 10:285-95. Doi: 2147/DMSO.S115890.

16. Bernardi JR, Ferreira CF, Nunes M, da Silva CH, Bosa VL, Silveira PP, et al. Impact of Perinatal Different Intrauterine Environments on Child Growth and Development in the First Six Months of Life-IVAPSA Birth Cohort: rationale, design, and methods. BMC Pregnancy Childbirth. 2012 Apr 2; 12:25. Doi: 1186/1471-2393-12-25.

17. Werlang ICR, Bernardi JR, Nunes M, Marcelino TB, Bosa VL, Michalowski MB, et al. Impact of perinatal different intrauterine environments on child growth and development: Planning and Baseline Data for a Cohort Study. JMIR Res Protoc. 2019 nov 12; 8(11):e12970. Doi: 2196/12970.

18. Institute of Medicine (US) and National Research Council (US) Committee to Reexamine IOM Pregnancy Weight Guidelines; Rasmussen KM, Yaktine AL, editors. Weight Gain During Pregnancy: Reexamining the Guidelines. Washington (DC): National Academies Press (US); 2009. Available from: https://www.ncbi.nlm.nih.gov/books/NBK32813/doi: 10.17226/12584

19. Conselho Nacional de Saúde (BR). Resolução n 466/2012. Diretrizes e Normas Regulamentadoras de Pesquisa Envolvendo seres Humanos. Brasília, 2012. [cited 2019 Nov 8]. Available from: http://conselho.saude.gov.br/resolucoes/2016/Reso466.pdf. 
20. Ferreira AP, Rombaldi JB, Ferreira CF, dos Santos DA, dos Santos AF, Pereira LW, et al. Fatores associados ao número de consultas pré-natais de mulheres tabagistas e não tabagistas atendidas em hospitais de Porto Alegre (RS), Brasil. Saúde em Redes. 2016; 2 (2): 167 - 178. Doi: 10.18310/2446-4813.2016v2n2p167-178.

21. Nascimento IB, Pacheco VC, Souza MLR, Pinheiro EB, e Silva TR, Fleig R, et al. Assistência pré-natal e resultado perinatal. Rev. Bras Promoç. Saúde. 2017 Fortaleza abr./jun; 30(2):187-194. Doi: 10.5020/18061230.2017.p187.

22. O'brien EC, Segurado R, Geraghty AA, Alberdi G, Rogozinska E, Astrup A, et al. Impact of maternal education on response to lifestyle interventions to reduce gestational weight gain: individual participant data meta-analysis. BMJ Open. 2019 Jun; 9:e025620. Doi: 1136/bmjopen-2018-025620.

23. Rasador S, Abegg C. Fatores associados à via de parto em um município da região nordeste do Estado do Rio Grande do Sul, Brasil. Bras. Saude Mater. Infant. 2019 Dec.;19(4):797-805. Doi: 10.1590/1806-93042019000400004.

24. Voerman E, Santos S, Patro Golab B, Amiano P, Ballester F, Barros H, et al. Maternal body mass index, gestational weight gain, and the risk of overweight and obesity across childhood: An individual participant data meta-analysis. PLoS Med. 2019 Feb 11;16(2):e1002744. Doi:

1371/journal.pmed.1002744.

25. Oliveira ACM, Pereira LA, Ferreira RC, Clemente APG, et al. Estado nutricional materno e sua associação com o peso ao nascer em gestações de alto risco. Ciênc. saúde coletiva. 2018 July; 23(7): 2373-2382. Doi: 10.1590/1413-81232018237.12042016.

26. Campos CAS, Malta MB, Neves PAR, Lourenço BH, Castro MC, Cardoso MA, et al. Ganho de peso gestacional, estado nutricional e pressão arterial de gestantes. Saúde Pública. 2019; 53:57. Doi: 10.11606/S1518-8787.2019053000880.

27. Marmitt LP, Gonçalves CV, Cesar JA. Healthy gestational weight gain prevalence and associated risk factors: A population-based study in the far South of Brazil. Rev. Nutr. 2016 jul/ago; 29(4):445-455. Doi: 1590/1678-98652016000400001.

28. Martino DD, Stampalija T, Rosti E, Casati D, Signorelli V, ZullinoS, et al. Bedside cardiovascular maternal interrogation in the first trimester to predict different phenotypes of hypertensive disorders in pregnancy. Pregnancy Hypertension: An International Journal of Women's Cardiovascular Health. 2016 out; 6(4):300-305. Doi: 1016/j.preghy.2016.06.002.

29. Pereira DBR. Tabagismo durante a gestação: fatores associados, peso ao nascer e peso na infância. [Dissertação] Programa de Pós-Graduação em Saúde Coletiva: Universidade Estadual de Feira de Santana; 2018.

30. Candle RV, Soriano-Vidal FJ, Cucarella EH, Castro-Sanches E, Martin-Moreno JM, et al. Tobacco use in the third trimester of pregnancy and its relationship to birth weight. A prospective study in Spain. Women and Birth 2015; 28(4):134-139. Doi: 1016/j.wombi.2015.06.003.

31. Moreira MEFH, Silva CL, Freitas RF, Macêdo MS, Lessa AC, et al. Determinantes socioeconômicos e gestacionais do peso ao nascer de crianças nascidas a termo. Medicina (Ribeiräo Preto). 2017 -abr; 
50(2): 83-90. Doi: 10.11606/issn.2176-7262.v50i2p83-90. 》

32. Diemert A, Lezius S, Pagenkemper M, Hansen G, Drozdowska A, Hecher K, et al. Maternal nutrition, inadequate gestational weight gain and birth weight: results from a prospective birth cohort. BMC Pregnancy and Childbirth. 2016; 16(1):224. Doi: 1186/s12884-016-1012-y.

33. Monteiro PGM. Impacto de intervenções focadas nos pais durante a gravidez e primeiros dois anos de vida da criança na incidência da obesidade infantil. [Dissertação]: Faculdade de Ciências da Nutrição e Alimentação da Universidade do Porto;

34. Ministério da Saúde (BR). Protocolos da Atenção Básica: Saúde das Mulheres. Ministério da Saúde, Instituto Sírio-Libanês de Ensino e Pesquisa - Brasília: Ministério da Saúde, 2016. [cited 2020 Mar 8]. Available from:

http://bvsms.saude.gov.br/bvs/publicacoes/protocolos_atencao_basica_saude_mulheres.pdf

35. Sorbye LM, Klungsoyr K, Samdal O, Owe KM, Morken NH, et al. Pre-pregnant body mass index and recreational physical activity: effects on perinatal mortality in a prospective pregnancy cohort. BJOG. 2015 Sep;122(10):1322-30. Doi: 1111/1471-0528.13290.

36. Tebbani F, Oulamara $\mathrm{H}$, Agli A. Factors associated with low maternal weight gain during pregnancy. Rev Epidemiol Sante Publique. 2019 Jul; 67(4):253- 260. Doi:1016/j.respe.2019.03.121.

37. Blumfield ML, Schreurs M, Rollo ME, MacDonald-Wicks LK, Kokavec A, Collins CE, et al. The association between portion size, nutrient intake and gestational weight gain: a secondary analysis in the WATCH study 2006/7. J Hum Nutr Diet. 2016 Jun; 29(3):271-80. Doi: 1111/jhn.12330.

38. Stang J, Huffman LG. Position of the Academy of Nutrition and Dietetics: Obesity, Reproduction, and Pregnancy Outcomes. J Acad Nutr Diet. 2016 Apr; 116(4):677-91. Doi: 1016/j.jand.2016.01.008.

\section{Figures}




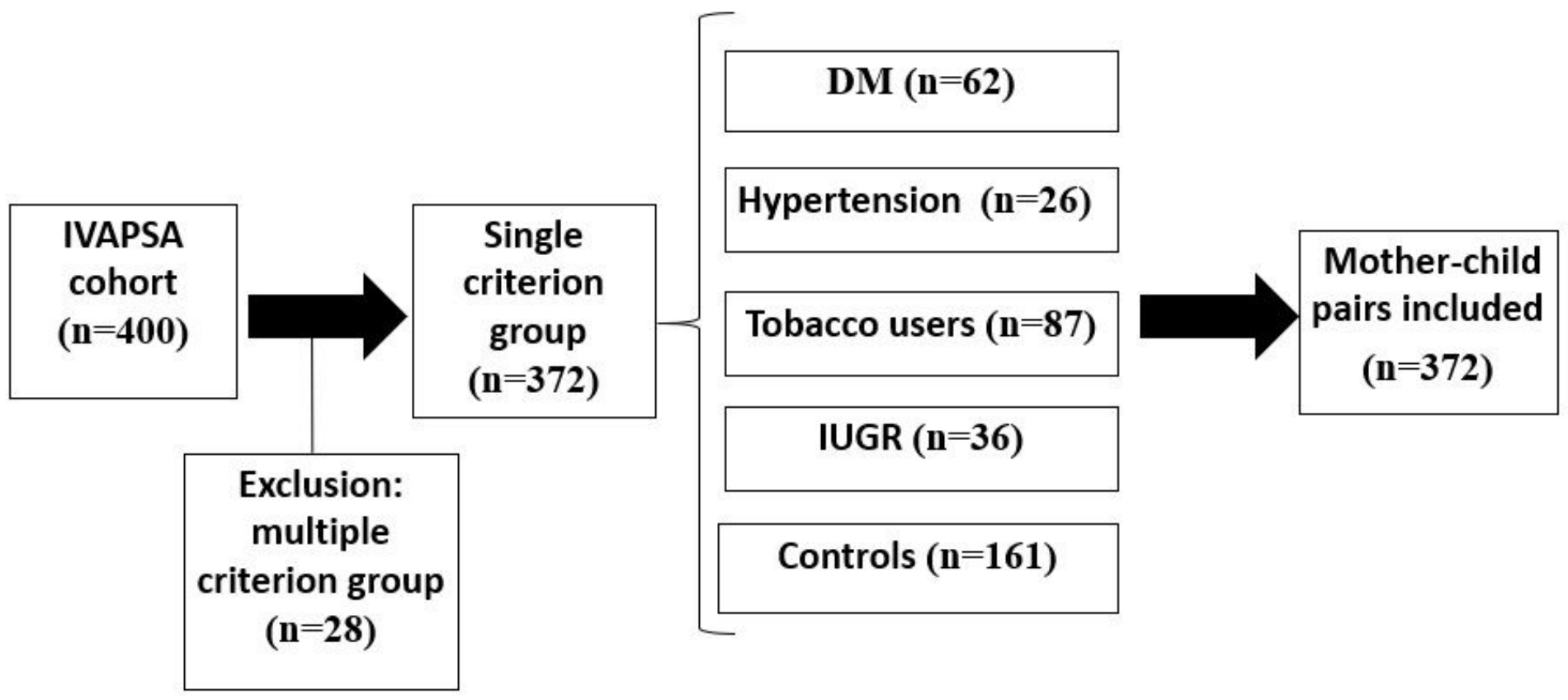

DM- diabetes mellitus ; IUGR- intrauterine growth restriction

Figure 1

Flowchart of sample selection. 


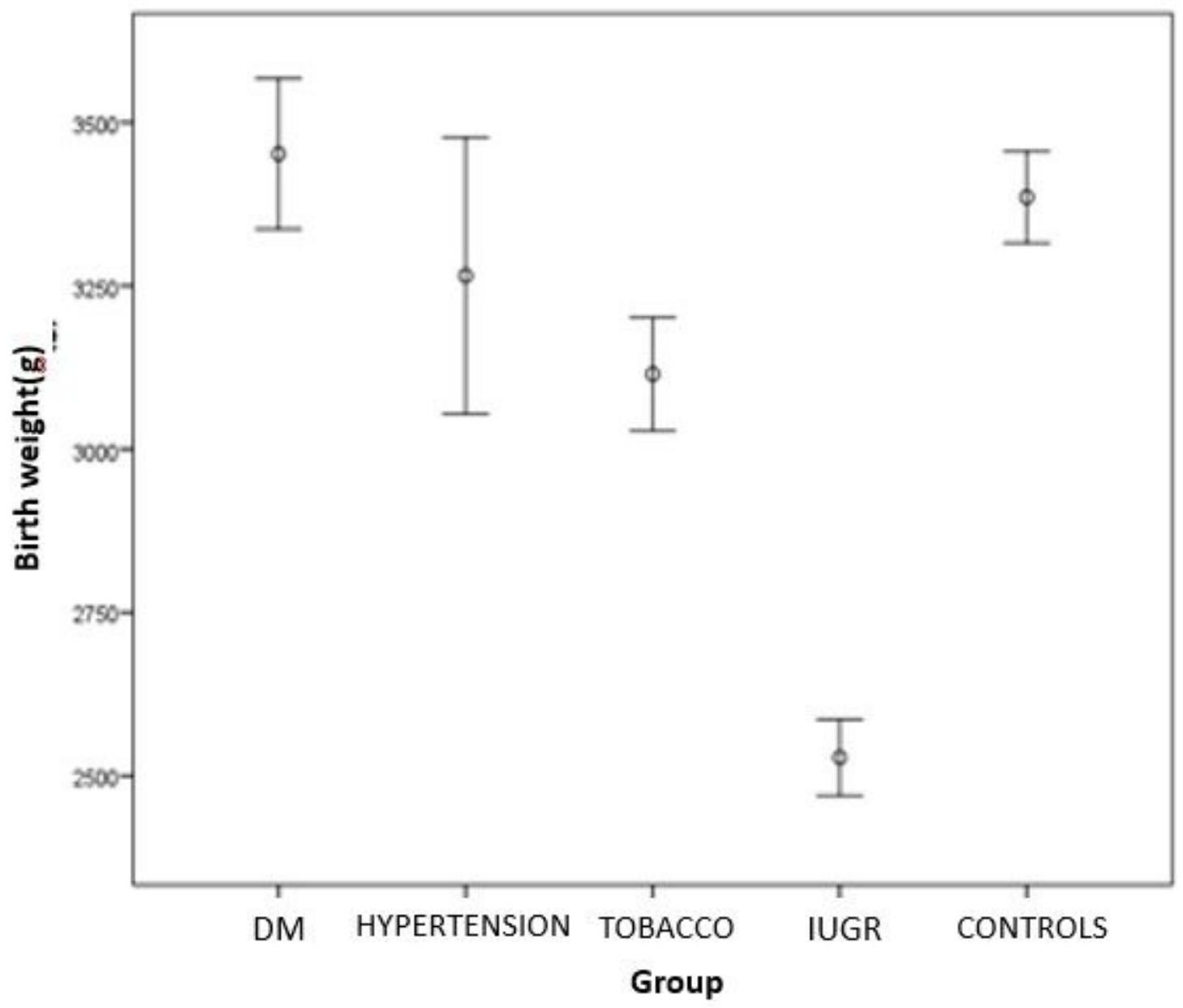

Figure 2

Birth weights

\section{Supplementary Files}

This is a list of supplementary files associated with this preprint. Click to download.

- STROBEchecklistcohort.pdf

- PBPARECERCONSUBSTANCIADOCEP2007000.pdf 